Discussion Paper No. 13-087

\title{
Elasticity of Substitution between Clean and Dirty Energy Inputs - A Macroeconomic Perspective
}

Chris Papageorgiou, Marianne Saam, and Patrick Schulte

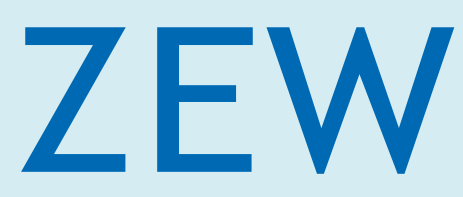

Zentrum für Europäische Wirtschaftsforschung $\mathrm{GmbH}$

Centre for European

Economic Research 
Discussion Paper No. 13-087

\title{
Elasticity of Substitution between Clean and Dirty Energy Inputs - A Macroeconomic Perspective
}

\author{
Chris Papageorgiou, Marianne Saam, \\ and Patrick Schulte
}

Download this ZEW Discussion Paper from our ftp server:

http://ftp.zew.de/pub/zew-docs/dp/dp13087.pdf

Die Discussion Papers dienen einer möglichst schnellen Verbreitung von neueren Forschungsarbeiten des ZEW. Die Beiträge liegen in alleiniger Verantwortung der Autoren und stellen nicht notwendigerweise die Meinung des ZEW dar.

Discussion Papers are intended to make results of ZEW research promptly available to other economists in order to encourage discussion and suggestions for revisions. The authors are solely responsible for the contents which do not necessarily represent the opinion of the ZEW. 


\title{
Elasticity of Substitution between Clean and Dirty Energy Inputs - A Macroeconomic Perspective*
}

\author{
Chris Papageorgiou ${ }^{\dagger}$ \\ International Monetary Fund \\ Marianne Saam \\ Centre for European \\ Economic Research (ZEW) \\ Patrick Schulte \\ Centre for European \\ Economic Research (ZEW)
}

October 23, 2013

\begin{abstract}
Recently Acemolgu, Aghion, Bursztyn and Hemous (AER 2012) formulated a model in which a high macroeconomic elasticity of substitution between clean and dirty production represents a crucial condition for green growth. Until now it has never been systematically estimated. Using a novel panel of cross-country sectoral data, we formulate specifications of nested CES production functions that allow to estimate a special case of this parameter: the elasticity of substitution between clean and dirty energy inputs. Contrary to what is expected based on the earlier interfuel substitution literature, we find evidence that this elasticity exceeds one.
\end{abstract}

JEL Classification: O44; O47; Q54; Q58.

Keywords: Clean and dirty energy inputs; aggregate elasticity of substitution; CES function; cross-country sectoral data; environmental policy.

*We thank Andreas Loeschel, Michael Huebler, Simon Koesler, Frank Pothen, Michael Schymura, Michael Ward and Irene Bertschek for their specific comments. We also benefited from discussions with participants at the workshop on 'The Macroeconomic Substitution Between Clean and Dirty Production' 2012, the conference on 'The Green Growth Challenge' 2012, and the International Economic Policy Research Seminar at Goethe University, 2013. The paper benefited greatly from financial support within the scope of the SEEK research programme. The views expressed in this project are the sole responsibility of the authors and should not be attributed to the International Monetary Fund, its Executive Board, or its management.

${ }^{\dagger}$ Corresponding author. email: cpapageorgiou@imf.org; address: 700 19th Street NW, Washington DC. 


\section{Introduction}

Advances in 'clean', environment-friendly technologies seem indispensable if disastrous climate change is to be prevented without compromising economic growth. Clean technological innovation will only be effective if there are economic incentives to reallocate resources from dirty to clean production. While incentives may depend on economic policies, they also depend on the production structure of an economy. Any model used to assess economic aspects of climate change incorporates a particular production structure. A recent publication by Acemoglu, Aghion, Bursztyn, and Hemous (2012) formulates the relation between growth and pollution in the framework of endogenous growth theory, in which different assumptions about the production structure can be discussed in an analytically stringent way. Within this framework the economy-wide elasticity of substitution between 'clean' and 'dirty' production represents a parameter on which the potential of clean innovation to prevent a climate disaster crucially depends. Dirty production is considered to take place when the atmospheric concentration of CO2 is increased as a result of using fossil fuels (coal, oil, natural gas). Calibrated simulations of the growth path under optimal environmental regulation indicate that the elasticity of substitution has to be quite high, around 10, in order to prevent an increase of global temperature of more than two degrees Celsius in a plausible scenario. While the particular threshold may depend on the specific model assumptions and calibrations of other parameters, an elasticity of substitution above one represents a necessary condition for long-term clean growth under more general conditions.

Substitution between clean and dirty production involves substitution between clean and dirty energy inputs and substitution between clean and dirty production processes. There is no straightforward empirical implementation of this general concept and to date empirical evidence is lacking. We make a first attempt to evaluate this parameter by estimating the elasticity of substitution between clean and dirty energy inputs. It represents a special case of the elasticity of substitution between clean and dirty production if production processes are constant.

In this paper we set out an approach how to quantify the elasticity of substitution between clean and dirty energy inputs from production functions that we can both estimate 
with available macroeconomic data and interpret through the lens of growth theory. To do so, we take advantage of the new World Input-Output Database (WIOD), which provides cross-country data on energy use by fuel type in an industry classification consistent with available productivity data. The data for our analysis cover up to 26 countries for the years 1995 - 2009. We estimate production functions separately for the electricity sector and the non-energy industries and provide a theoretical argument how the elasticities of these two production functions relate to the economy-wide elasticity of substitution between clean and dirty energy inputs. Our main finding is that our baseline elasticity estimates are significantly greater than unity, around 2 for the electricity generating sector and close to 3 for the non-energy industries.

\section{Related Research}

\subsection{Theory}

While the literature on environmental policy first developed from a microeconomic perspective, in recent years it has increasingly focused on macroeconomic questions. ${ }^{1}$ Our work is inspired by the pioneering work of Acemoglu, Aghion, Bursztyn, and Hemous (2012) (henceforth AABH) who place the question of long-run green growth in the center stage of modern growth theory. While the relation between clean innovation and growth was already discussed in Aghion and Howitt (1998) and a number of other models, AABH use the modeling framework of directed technical change that allows to systematically investigate how the interplay between technology and policy interventions affects the market forces driving innovation.

In the context of this paper, we will refer only to those properties of the model that are most relevant for understanding the role of the elasticity of substitution. A unique final good is produced competitively using clean and dirty inputs in a CES technology. Clean input is produced using labor and a continuum of non-polluting machines. Dirty input is produced in a different sector using labor and a continuum of polluting machines. Utility is a function of consumption and quality of the environment. In line with standard models of endogenous technical change, machines for both sectors are supplied by monopolisti-

\footnotetext{
${ }^{1}$ Two excellent surveys on technical change and other macroeconomic issues in environmental economics have been contributed by Popp, Newell, and Jaffe (2010) and Heutel and Fischer (2013).
} 
cally competitive firms. Scientists develop patents for better machines. Each scientist decides whether she conducts research in the field of dirty or clean technology. Innovation follows a "building on the shoulders of giants"-process: Past successful innovation raises the expected profitability of innovation in the present.

The paper investigates the possibility of achieving long-run growth without disastrous climate change by suitable taxes and subsidies. The authors highlight four situations that can be distinguished in the model: (1) An elasticity of substitution below one: Long-term growth is only possible with both clean and dirty inputs growing without bound. (2) An elasticity of substitution of at least one not exceeding the inverse of the labor share (with a standard calibration for the labor share of $2 / 3$ it would amount to 3/2): Even if a research subsidy redirects scientists to clean innovation, the resulting improvements in productivity in the final goods sector indirectly encourage the increase of dirty energy inputs, since the final good is partly invested in dirty machines. ${ }^{2}$ (3) An elasticity of substitution exceeding the inverse of the labor share: If the subsidy redirects scientists to the clean sector, this freezes productivity in the dirty sector. The clean sector, once it has overtaken the dirty sector in terms of research profitability, becomes ever more productive. The subsidy can then be stopped. The productivity effect and the market size effect are acting in favor of the clean sector and dominate the price effect, which reflects the incentives to innovate in the production of the more backward and expensive good. (4) A very high elasticity of substitution (around 10 according to simulations in AABH): Though clean long-run growth is feasible with a research subsidy in case (3), it does not necessarily constitute the optimal policy choice of a social planner given a utility function that values both consumption and absence of pollution. Only with a very high elasticity of substitution, the short-term reduction in productivity compared to the laissez-faire path is low enough in order to make the immediate redirection of all scientists to clean innovation an optimal policy choice. This in turn is necessary to contain long-term climate change below two degree Celsius. A recent extension of the theory to a north-south model discusses in how far local regulation in the 'North' can prevent a climate disaster and to which extent global coordination is necessary (Acemoglu, Aghion, and Hemous 2013).

Given the difficulties to estimate substitution parameters of energy input and to pos-

\footnotetext{
${ }^{2}$ This is a variant of the rebound effect frequently discussed in energy policy.
} 
tulate their stability over time, some theoretical work explicitly starts from the conservative assumption of low substitution possibilities and identifies other technological channels thought to make long-run growth possible without depleting non-renewable resources or causing excessive pollution. In a model focusing on sustainable growth with non-exhaustible resources, Bretschger and Smulders (2012) assume a low elasticity of substitution between non-renewables and intermediate inputs that fosters structural change and long-run growth in the presence of endogenous technical progress and knowledge spillovers. Some recent work critically comments on AABH's approach to model clean growth as a process driven by factor substitution. Hourcade, Pottier, and Espagne (2011) cast doubt on the possibility to measure the elasticity of substitution between clean and dirty production. What in their view comes closest to it in previous empirical research is the price elasticity of gasoline demand for which they report a value of 0.5. Mattauch, Creutzig, and Edenhofer (2012) construct a model with a similar CES production technology as AABH that assumes learning-by-doing spillovers instead of directed technical change. Contrary to AABH's main results, it follows from their calibration that a permanent implementation of taxes and subsidies is optimal.

\subsection{Empirics}

The literature on interfuel substitution and capital-energy substitution that emerged in the 1970s was interested in understanding the economic reactions to the oil crisis. The goal was to assess how oil could be substituted by coal, gas and electricity or by more energy-efficient production methods. The first studies exploited substitution of fuels at given capacities in the electricity sector (Atkinson and Halvorsen 1976) as well as long-run substitution estimated from cross-country data for the electricity sector (Griffin 1977) and the non-energy sector (Pindyck 1979). Griffin (1977) finds high elasticities for coal and gas with respect to the oil price but low elasticities between coal and gas. Fuss (1977) reports cross-price elasticities that are higher within fossil fuels than between fossil fuels and electricity. These studies all use some variant of the translog function.

From the late 1980s on, several studies aim at resolving the puzzle of implausible elasticity estimates such as positive own-price elasticities or negative Morishima elasticities. Considine (1989) discusses three main causes: concavity violations of the translog func- 
tion, bias resulting from policies that regulate energy supply and the structure of industrial fuel and energy consumption. Jones (1995) finds evidence that excluding fuels used for non-energy purposes yields larger substitution elasticities. Steinbuks (2010) introduces a further differentiation of fuel use for energy purposes in different manufacturing processes. Heating processes account for more than two thirds of total energy consumption in manufacturing. In these processes, positive shares of all four energy inputs (petroleum, coal, gas, electricity) are observed, while other processes require specific fuels.

In a study based on data for the years 1980 to 2006, Serletis, Timilsina, and Vasetsky (2011) find time-series estimates of Morishima elasticities in the residential and transportation sectors that exceed those in the electricity generating and industrial sectors of many countries. A recent meta-analysis shows that cross-section estimates tend to be higher than panel estimates which are in turn higher than time series estimates (Stern 2012). Already in early studies, this difference has been interpreted as reflecting long-run versus short-run elasticities (Griffin and Gregory 1976). Moreover, elasticities are lower at higher levels of aggregation. At the level of the macroeconomy or the aggregated industrial sector, only the coal-gas elasticity exceeds one significantly.

The general elasticity of substitution between clean and dirty technology modeled by AABH depends on substitution between clean and dirty fuels and substitution between fuels and other inputs. In a modern economy the most important substitution of the latter kind is the substitution between energy and capital. Although we limit estimated clean-dirty substitution to interfuel substitution, research on capital-energy substitution is relevant to our approach since we control for the influence of capital. Moreover the methodological issues encountered when estimating both kinds of elasticities are similar.

Estimating Allen partial elasticities of substitution, Berndt and Wood (1975) find complementarity between capital and energy but substitutability between energy and labor. Later work discussed the choice of the appropriate partial substitution elasticities (Taylor and Thompson 1995, Frondel 2010), the dependency of results on data and econometric design (Koetse, De Groot, and Florax 2008) and the parametrization and interpretation of translog estimates (Frondel and Schmidt 2006). Closer to the structures employed in applied theory are empirical studies based on nested CES functions (Kemfert 1998, Van 
der Werf 2008). With three inputs, Van der Werf (2008) finds most support for nesting capital and labor in a subfunction or having a one-level function with three inputs. Recently Hassler, Krusell, and Olovsson (2012) estimate a nested CES function for capital, labor and energy based on quantity and price data for the US. Capital-labor substitution is assumed to be unity and short-run substitution between this composite and fossil fuels is found to be close to zero. Energy-saving technical change appears to have reacted strongly to the oil crisis and exhibits a negative medium-run correlation with technical change directed towards other inputs. These insights are then incorporated into a model of directed technical change. The parsimonious specification in this study and the perspective on long-run growth are close to our approach, with the main difference that we focus on substitution between clean and dirty energy inputs and that we do not estimate directed technical change. The assumptions regarding price and path dependency of directed clean technical change from AABH's model are also tested in a microeconomic analysis by Aghion, Dechezleprêtre, Hemous, Martin, and Van Reenen (2012).

To our knowledge there are only two previous studies determining the elasticity of substitution between clean and dirty energy inputs empirically. Pelli (2012) extends the model developed by AABH to a multi-sector setting. For the electricity sector, he then introduces several assumptions that allow the calibration of the non-US elasticities from the US elasticity. The calibrated elasticities for the electricity sector concentrate around 0.51. Lanzi and Sue Wing (2010) investigate directed technical change in the energy sector. They develop a dynamic model in which energy demand is satisfied with production derived from renewable and fossil-fuel energy. A steady-state condition is used to estimate the relationship between relative patenting activity in clean and dirty energy production and the relative price of fossil fuels. While the main purpose of the paper is to investigate whether clean innovation reacts to rising fossil fuel prices, the estimating equation also yields a value for the elasticity of substitution between clean and dirty inputs in the energy sector of 1.6. The econometric estimate for a panel of OECD countries is obtained under the particular assumptions of the steady state of a model of directed technical change. 


\section{Conceptual Framework}

\subsection{Substitution between Clean and Dirty Energy Inputs}

Thinking about substitution between clean and dirty energy inputs from a macroeconomic perspective, one might consider that the productivity of energy does not depend much on its source or its intensity of pollution. As AABH argue: 'For example, renewable energy, provided it can be stored and transported efficiently, would be highly substitutable with energy derived from fossil fuels. This reasoning would suggest a (very) high degree of substitution between dirty and clean inputs, since the same production services can be obtained from alternative energy with less pollution' (p.135). The aspect of transportation and storage pointed out in this quote is a critical one for renewable energy. In energy production, the difficulties in storing energy from renewable sources leads to a misalignment in time and space with electricity demand. Discussing this problem, Mattauch, Creutzig, and Edenhofer (2012) consider that investments in better infrastructure, e.g., grid integration across large areas, could increase the substitution possibilities between clean and dirty energy production. Even in cases where demand is adequate to supply, the fixed costs are currently higher for clean energy plants than for dirty energy plants. Meanwhile the variable costs of clean energy production are generally lower. One has to be careful not to interpret these properties in any simple way as evidence on the elasticity of substitution. The elasticity of substitution does not express the level of relative average or marginal productivity. Rather a high elasticity of substitution means that the relative marginal productivity of an input does not decline much if it is used in increasing relative intensity.

Still there are reasons to consider a limited elasticity of substitution: if clean electricity generation involves both nuclear and renewable sources, marginal productivity of investment into clean capacity may be declining. Capacity may first be installed in places where the supply of wind or sun is advantageous and than in less advantageous places. Moreover, fossil fuels with relatively low fixed but higher variable cost better serve as peak load fuels not only compared to renewables but also compared to nuclear energy (IEA/ OECD NEA 2010). If the ratio of clean to dirty energy inputs rises to high levels in the entire economy, clean energy production has to serve both base and peak demand 
and will experience declining efficiency.

In the energy-using sectors, a wide range of processes can be run using electricity but some industrial processes require particular fossil fuels (e.g. the cement production). And in transportation the internal combustion engine still represents the dominant technology to which current infrastructure is mainly adapted (Mattauch, Creutzig, and Edenhofer 2012). On the other hand, structural change may reduce the weight of dirty production processes in the economy. At macroeconomic level it is therefore a priori uncertain whether the known cases of limited substitution lead to an overall low elasticity of substitution between clean and dirty energy inputs. The aim of this paper is to provide first econometric evidence on this issue using a production function approach.

\subsection{Aggregate Production Function Approach}

The model by AABH does not lend itself to estimation although it is possible to make some informed guesses about the magnitude of the elasticity of substitution between clean and dirty production based on different strands of previous empirical literature. Developing a model which is encompassing at a theoretical level and can at the same time be estimated with our data goes beyond the scope of the present paper. In this section, we offer a theoretical argument based on a stripped-down production function to illustrate how the elasticity of substitution we estimate separately for two sectors relates to an aggregate elasticity of substitution between clean and dirty energy inputs.

Our approach is based on the insight that long-run growth with rising factor intensities (e.g. with a rising capital intensity or a rising clean-to-dirty ratio) is only possible if the factors are sufficiently substitutable. In the neoclassical growth model without technical change, a positive limit of the declining marginal productivity of factors of production represents a necessary condition for long-run growth. With CES production functions in a two-factor setting, this corresponds to a constant elasticity of substitution between the factors that is larger than one. In standard models of biased technical change, the limit of marginal products plays a similar role since factor intensities continue to change in the long run. Previous work extends the analysis of factor substitution and the limiting behavior of marginal products to a two-level CES function with capital, skilled and unskilled labor (Papageorgiou and Saam 2008) and to a technology that is CES both in intermediate and 
final goods (Miyagiwa and Papageorgiou 2007). We transpose these results to a nested aggregate production function for the energy and the non-energy sector. The production functions formulated here are quite close to those we will use for estimation.

The main simplification we are making compared to our empirical setting is that we assume substitution between energy and non-energy inputs to be zero. This allows us to isolate the elasticity of substitution between clean and dirty energy inputs in a twofactor setting. Moreover, we assume that the energy sector delivers only clean energy (electricity) to the non-energy sector. This is in line with our estimation strategy, which provides estimates for the electricity sector only and not for the rest of the energy sector. Output of the electricity sector (corresponding to clean input into the final sector, $X_{F C}$ ) is modeled by a CES production function, assuming that clean and dirty inputs $\left(X_{E C}, X_{E D}\right)$ are used in fixed proportion with other inputs in clean and dirty electricity generation:

$$
X_{F C}=A_{E}\left(\omega X_{E C}^{\psi_{E}}+(1-\omega) X_{E D}^{\psi_{E}}\right)^{\frac{1}{\psi_{E}}}
$$

Since it is well-known that clean energy production has higher fixed cost and lower marginal cost than dirty production, one may object that the production function should account for these characteristics and should not treat clean and dirty inputs in electricity production in a symmetrical way. Production functions that will arise from such a construction, however, imply restrictions that predetermine the elasticity of substitution. In many cases, the elasticity of substitution converges to one as one of the input intensities increases (see, e.g., Revankar (1971) for a so-called VES function). Thus we prefer the CES specification.

The non-energy sector is producing with a Leontief technology using energy and other inputs $Z$. Energy inputs in turn are represented by a CES aggregate of electricity $\left(X_{F C}\right)$ and dirty energy input $\left(X_{F D}\right)$ :

$$
Y=A_{F} \min \left\{Z,\left[\beta X_{F D}^{\psi_{F}}+(1-\beta) A_{E}^{\psi_{F}}\left(\omega X_{E C}^{\psi_{E}}+(1-\omega) X_{E D}^{\psi_{E}}\right)^{\frac{\psi_{F}}{\psi_{E}}}\right]^{\frac{1}{\psi_{F}}}\right\}
$$

With constant $Z$, function (2) represents a special case of the multilevel CES function considered in Miyagiwa and Papageorgiou (2007). Their analysis reveals that in a multilevel CES function with two factors of production, the overall elasticity of substitution represents a weighted mean of the elasticities within the single CES functions. In our 
case, the aggregate elasticity of substitution between clean and dirty energy inputs is a weighted mean of the elasticity in the electricity sector, $1 /\left(1-\psi_{E}\right)$, and the elasticity in the final sector $1 /\left(1-\psi_{F}\right)$ (The formal application of the result by Miyagiwa and Papageorgiou (2007) to our case is shown in the Appendix).

With the technology (2) and variable $Z$, the aggregate elasticity of substitution between clean and dirty inputs corresponds to the more general elasticity of substitution between clean and dirty production if inputs $Z$ are clean. Future research could address the question how to estimate the general elasticity when substitution between the energy aggregate and the other inputs $Z$ occurs and when these inputs are in part dirtily produced. The aggregate elasticity of substitution will then again be a weighted average of the elasticity within energy inputs, within $Z$ and between energy and other inputs $Z$.

While we now assume $Z$ to be clean, a more general production function will attribute some pollution to the production of the inputs $Z$. Except for imported inputs, this would, however, withdraw some energy inputs from the energy subaggregate. So a priori it is not clear whether the more general elasticity is higher or lower than the one we consider. Our informed guess is that the two elasticities within the subaggregates will not be lower but the elasticity between energy and non-energy inputs might be. But we also expect a function that serves to empirically measure the elasticity of substitution between clean and dirty production to take a different shape than (2), since pollution at different stages of the value chain has to be considered in a integrated way. As a consequence, quantities of clean and dirty units might not represent direct measures of inputs anymore but measures of unwanted outputs in the case of pollution.

Our empirical specification departs from (2) in allowing for substitution between energy and non-energy inputs. We are, however, not concerned with generalizing the concept of a two-factor elasticity of substitution to a partial elasticity of this extended function (for this issue see, e.g., Taylor and Thompson (1995) or Frondel (2010)). Rather we are interested in the elasticity of substitution within the energy aggregate. In the following we will use the term elasticity of substitution between clean and dirty energy inputs to refer to this parameter that remains constant within multilevel CES functions, although partial elasticities are in general variable. 


\section{Estimation Strategy}

\subsection{Baseline Approach}

In order to bring the elasticity of substitution discussed in the previous section to the data, we need to decide on the level of aggregation for inputs and outputs, the functional form of production technology and the restrictions we impose in order to identify the function. We aim at identifying substitution between clean and dirty energy inputs at the level of the entire economy. We simplify by using a binary distinction: Clean energy inputs are those not causing CO2 emissions, dirty energy inputs are those causing such emissions. This affects in particular the classification of natural gas as dirty, which however causes less emissions than the use of coal and oil. The technology of the energy sector differs fundamentally from the technologies of the other sectors since it uses primary energy as an input and produces derived energy. The other sectors use derived energy (and, to a smaller extent, primary energy) as an input and produce an output that in general is not energy. The sector 'energy, gas and water supply' (sector E of the NACE 1.1. classification) causes nearly half of all emissions in the advanced countries (source: WIOD). In line with previous research, we study the electricity generating sector only, ignoring gas and water supply.

A limitation of our approach is the way our data account for trade in energy inputs and for private energy consumption. Electricity supply to households is included in the electricity sector. Gas supply is not included and neither gasoline supply for transport, since we exclude the industry 'coke, refined petroleum and nuclear fuel' (NACE 23) with an extremely high dirty-to-clean ratio of inputs from the non-energy sector. We include imported energy inputs but we do not account for the fact that imported electricity may cause emissions at production in other countries. The average ratio of imported electricity to generated electricity lies below 30 percent in all countries observed except Luxembourg, in a number of countries even below 10 percent.

We use industry-level observations for the non-energy industries to estimate an aggregate production function for the non-energy sector. This approach implies that substitution between clean and dirty energy inputs can occur at three levels: industries can become cleaner over time, the same industries may have different levels of clean energy use 
in different countries and a country's production can become cleaner by shifting resources towards sectors with a higher share of clean energy inputs.

In choosing a functional form we depart from the majority of previous work in considering variants of nested CES functions (as Kemfert (1998), Van der Werf (2008)) and in not imposing first-order conditions for factor demand. Since CES functions are highly nonlinear and hard to identify (León-Ledesma, McAdam, and Willman 2010a), we use linear translog approximations as robustness checks. In the perspective of growth theory, it is not our primary interest to know how the use of energy inputs reacts to their prices. Rather we want to know whether the technological capabilities of an economy are such that it could replace dirty energy input with clean energy input without inducing or accelerating a decline of marginal productivity of energy. With a CES function, this is the case when its substitution parameter is high. We think that market distortions and measurement error can be large enough in the energy market to cast serious doubt on the equality between the energy price and its marginal productivity. Against this background, our main estimation strategy relies on input and output quantities only.

Contrary to the theoretical model we are inspired by, we assume technological change to be neutral. The nonlinear nature of the CES function, the collinear nature of time and factor accumulation and the limited number of observations in the energy sector make the simultaneous identification of elasticities of substitution and biased factor-augmenting technical change for more than two factors of production difficult. It may be easier when imposing first-order conditions or using direct measures of technical change in combination with a steady state assumption (as in Lanzi and Sue Wing (2010)), but each of these approaches implies other restrictions not needed in our approach. We consider an estimation with neutral technological change as a useful starting point. A meta-analysis by Stern (2012) of previous interfuel substitution studies found mixed results from omitting technical change from the energy sub-model, with a tendency towards a negative effect on the elasticity of substitution. 


\subsection{Empirical Specifications}

\subsubsection{Electricity Sector Specifications}

We start from the most parsimonious specification possible, since the identification of aggregate CES functions quickly becomes difficult when adding variables. The main inputs into electricity production that matter for clean-dirty substitution are clean and dirty production capacity. The following CES production function includes these two inputs and neutral technical change only (all CES functions are written in logarithmic form):

$$
\ln Y_{i t}=a_{i}+d t+\frac{1}{\psi} \ln \left(\omega K_{C i t}^{\psi}+(1-\omega) K_{D i t}^{\psi}\right)+\varepsilon_{i t}
$$

where $i$ denotes the country, $t$ denotes the year, and $\varepsilon$ is the error term. $Y_{i t}$ is the output generated, $K_{C i t}$ and $K_{D i t}$ represent the capital input by clean and by dirty technologies. The elasticity of substitution between both types of capital, $\sigma_{C D}$, is constant and equal to $\frac{1}{1-\psi}$. Since the share of labor income is negligible and labor is not expected to be substitutable in the electricity sector, we exclude it from the production function. Moreover the function implicitly assumes a fixed ratio between capital and fuel input. For clean electricity production, the cost for primary energy input is often zero (e.g., sunlight, wind) or negligible. Thus our assumption is more restrictive for dirty electricity production where there might be an economically meaningful tradeoff between fuel use and investment in better capacity. We conduct a robustness check assuming a unitary elasticity of substitution between capital and fuel in electricity generation, similar to the function used by Stokey (1996). The resulting Cobb-Douglas-in-CES specification is the following:

$$
\ln Y_{i t}=a_{i}+d t+\frac{1}{\psi} \ln \left(\omega K_{C i t}^{\psi}+(1-\omega)\left(K_{D i t}^{\alpha} E_{D i t}^{1-\alpha}\right)^{\psi}\right)+\varepsilon_{i t},
$$

where $E_{\text {Dit }}$ represents fuel input used in dirty electricity generation.

Nonlinear estimation accounts in the most exact way for the properties of the CES function, yet it is more difficult to implement because of numerical problems. As a robustness check we estimate a variant of the translog function, the so-called Kmenta approximation, which represents a linear first-order approximation of (3) around $\psi=0$ (Kmenta 1967):

$$
\ln Y_{i t}=a_{i}+d t+\omega \ln K_{C i t}+(1-\omega) \ln K_{D i t}+(1-\omega) \frac{\psi}{2}\left(\ln K_{C i t}-\ln K_{D i t}\right)^{2} .
$$


This expression can then be rewritten in per dirty capital units (indicated by lowercase variables) by dividing through $K_{D i t}$ to obtain the following specification for linear estimation:

$$
\ln y_{i t}=a_{i}+d t+\beta_{1} \ln k_{i t}-\beta_{2}\left(\ln k_{i t}\right)^{2}+\varepsilon_{i t} .
$$

From the parameter estimates, we can compute the CES parameters in the following way:

$$
\begin{aligned}
\sigma_{C D} & =\beta_{1}\left(1-\beta_{1}\right) /\left(\beta_{1}\left(1-\beta_{1}\right)-2 \beta_{2}\right) \\
\omega & =\beta_{1} .
\end{aligned}
$$

The disadvantage of the translog function is that its two-factor elasticity of substitution converges to one for large input ratios and that it satisfies the conditions of a neoclassical production function only locally.

\subsubsection{Non-Energy Sector Specifications}

For the non-energy sector, we choose as a baseline specification one that allows to identify substitution between clean and dirty energy inputs and assumes a value of one for the other substitution elasticities. This strategy is close to the one used by Hassler, Krusell, and Olovsson (2012) with the difference that they estimate substitution between energy and non-energy inputs. Ideally we would observe gross output and all relevant inputs (capital, labor, clean energy, dirty energy and the other intermediate inputs) with the reliability of national accounts data. Since our data only allow for a more approximate split of intermediate input into energy on the one hand and materials and services on the other hand, we use two alternative dependent variables: value added plus energy cost (as e.g. used in Van der Werf (2008)) and gross output. Written down for gross output, our baseline CES-in-Cobb-Douglas specification with constant returns to scale and neutral technical change is the following:

$$
\begin{aligned}
\ln Y_{i j t}=a_{i}+a_{j}+d t & +(1-\alpha-\gamma-\theta) \ln L_{i j t}+\alpha \ln K_{i j t} \\
& +\theta \ln M S_{i j t}+\gamma\left[\frac{1}{\psi} \ln \left(E_{C i j t}^{\psi}+E_{D i j t}^{\psi}\right)\right]+\varepsilon_{i j t},
\end{aligned}
$$

where $Y_{i j t}$ represents gross output in country $i$ and industry $j, t$ is a time trend, $L_{i j t}$ denotes labor input, $K_{i j t}$ is the capital input, $M S_{i j t}$ represents intermediate materials and services input and $E_{C i j t}$ and $E_{D i j t}$ represent the clean and dirty energy inputs (All 
specifications for value added plus energy cost follow in a straightforward way and are not written down here.). Note that contrary to the standard CES function our specification for the energy subaggregate does not include multiplicative weights for the two input terms. The reason becomes intuitive when considering the case of infinite substitution: energy inputs are measured in homogenous units of terajoules (TJ), and in the case of infinite substitution we would expect the total productive services of energy inputs to be the unweighted sum of these inputs.

Since a large literature reports low elasticities of substitution between energy and nonenergy inputs (see literature section), we run a robustness check relaxing the assumption of a unitary elasticity between the energy aggregate and the remaining inputs. This results in the following function for logarithmic gross output:

$$
\ln Y_{i j t}=a_{i}+a_{j}+d t+\frac{1}{\phi} \ln \left[\zeta\left(K_{i j t}^{\alpha} M S_{i j t}^{\theta} L_{i j t}^{(1-\alpha-\theta)}\right)^{\phi}+(1-\zeta)\left(E_{C i j t}^{\psi}+E_{D i j t}^{\psi}\right)^{\frac{\phi}{\psi}}\right]+\varepsilon_{i j t} .
$$

As before $\sigma_{C D}=\frac{1}{1-\psi}$ is the elasticity of substitution of interest. On the other hand, $\sigma_{K L M, E}$ which is equal to $\frac{1}{1-\phi}$, represents the elasticity of substitution between the energy and the non-energy aggregate. As for the electricity sector, we run a robustness check with a linear approximation of the baseline CES-in-Cobb-Douglas form:

$\ln \frac{Y_{i j t}}{L_{i j t}}=a_{i}+a_{j}+d t+\beta_{1} \ln \frac{K_{i j t}}{L_{i j t}}+\beta_{2} \ln \frac{E_{C i j t}}{L_{i j t}}+\beta_{3} \ln \frac{E_{D i j t}}{L_{i j t}}+\beta_{4}\left(\ln \frac{E_{D i j t}}{E_{C i j t}}\right)^{2}+\beta_{5} \ln \frac{M S_{i j t}}{L_{i j t}}+\varepsilon_{i j t}$,

where $\beta_{2}=\beta_{3}$. The CES-in-Cobb-Douglas parameters can then be derived as:

$$
\begin{aligned}
\alpha & =\beta_{1} \\
\gamma & =2 \beta_{2} \\
\theta & =\beta_{5} \\
\sigma_{C D} & =1 /\left(1-\beta_{4} / 8 \beta_{3}\right) .
\end{aligned}
$$

\section{Data}

Both parts of the analysis make use of input and output data that are mainly taken from the World-Input-Output Database (WIOD) and the GGDC Productivity Level database. The WIOD, a new cross-country data set constructed in a project funded by the European 
Commission, makes available for the first time internationally comparable fuel use data together with standard productivity data at the level of up to 35 industries. It covers a time period of 15 years $\left(1995\right.$ - 2009). ${ }^{3}$ The WIOD and the GGDC Productivity Level Database use the same industry classification system (NACE 1.1), cover nearly the same industries and are constructed in a methodologically similar way which allows their consistent combination. ${ }^{4}$ From the GGDC Productivity Level Database industrial Purchasing Power Parities (PPPs) for up to 30 countries can be taken to convert monetary variables from the WIOD into internationally comparable units. For the construction of the data set for the electricity generating sector the EU KLEMS database (March 2011 release), the IEA Electricity Information Statistics database and the EIA Annual Energy Outlook are used in addition. The raw data taken from all sources are summarized in Table 1.

\subsection{Electricity Generating Sector}

To estimate substitution possibilities between clean and dirty electricity generation we need input and output information for both types of production processes. As output measure we choose physical output since real value added in this highly regulated sector may be influenced by many factors not related to productivity. Information on the electricity generated by technology is taken from the IEA Electricity Information Statistics. The main input measures, clean and dirty capital, are approximated by another physical measure: 'net installed technology specific generation capacity' in megawatt (MW). ${ }^{5}$ It is important to emphasize that this measure is not tautological to physical output since an equivalence only holds under uninterrupted production and ideal conditions as for example discussed by Söderholm (2001). Still, installed capacity is not measured in units that are homogenous in cost. The installed capacity should be strongly correlated with

\footnotetext{
${ }^{3} \mathrm{~A}$ detailed description of the contents and the construction of the database can be found in Timmer (2012) and Dietzenbacher et al. (2013).

${ }^{4}$ The sources and methods used in the construction of the GGDC Productivity Level Database are described by Inklaar and Timmer (2008). The database complements the WIOD by providing Purchasing Power Parities. The Groningen Growth and Development Center which maintains the GGDC Productivity Level Database also has a leading role in the consortium responsible for the construction of the WIOD database, underlining the relatedness of these two databases.

${ }^{5}$ The IEA defines the net installed generation capacity as: "[...]It is the maximum active power that can be supplied, continuously, with all plants running, at the point of outlet to the network.[...]" (IEA / OECD 2013). It has been used frequently as a capital input proxy in the electricity sector, see e.g. Dhrymes and Kurz (1964), Atkinson and Halvorsen (1976), Bopp and Costello (1990), Söderholm (2001), Färe, Grosskopf, Noh, and Weber (2005), Considine and Larson (2009), Pettersson, Söderholm, and Lundmark (2012).
} 
Table 1: Data Description

Variable Description and Unit of Measurement

\section{World Input-Output Database}

Gross output at current basic prices (in millions of national currency)

Gross value added at current basic prices (in millions of national currency)

Intermediate inputs at current purchasers prices (in millions of national currency)

Use of products by industry at current purchasers prices (in millions of national currency)

Real fixed capital stock (1995 prices)

Total hours worked by persons engaged

Price levels gross output $(1995=100)$

Price levels value added $(1995=100)$

Price levels intermediate inputs $(1995=100)$

Labor compensation (in millions of national currency)

Capital compensation (in millions of national currency)

Price levels of gross fixed capital formation $(1995=100)$

Emission relevant energy use by fuel type (in TJ)

\section{GGDC Productivity Level Database}

Purchasing Power Parities for country industry combinations (national currency per US\$, 1997)

EU KLEMS March 2011 Update (only for industry 40x)

Capital compensation (in millions of national currency)

\section{IEA Electricity Information Statistics}

Net electricity production by generation technology (GWh) - Total plants

Net electrical capacity by generation technology (MW) - Total plants

Fuel input by fuel type (TJ) - Total plants

\section{EIA Annual Energy Outlook}

Capital Cost by generation technology (in current US\$ per kW) 
Variable Description and Unit of Measurement

Real fixed capital stock assigned to clean technologies (EIA based)

Real fixed capital stock assigned to dirty technologies (EIA based)

Electricity generation by all technologies (in GWh)

Net installed capacity of clean technologies (in MW)

Net installed capacity of dirty technologies (in MW)

Fuel input into dirty technologies (in TJ)

monetary capital employed, since installing additional generation capacity requires additional investments. On the other hand, it should be expected that clean technologies have higher capital costs than dirty technologies (which in turn incur higher fuel costs). Since we have only limited information about clean and dirty installation cost per megawatt and moreover lose some data points in adding this information, we present estimations with capacity data as baseline results, using approximated real capital stocks for a robustness check.

These 'real' clean and dirty capital stocks are derived by valuing installed capacities with technology specific investment cost estimates published by the US Energy Information Agency. ${ }^{6}$ They offer temporal variation since they are updated every year. But we need to assume that they are equal across countries since we do not have similar information for other countries. The monetary values derived from this source are then normalized in such a way that the clean and the dirty capital stocks together equal the capital stocks obtained from EU KLEMS in order to ensure consistency with the remaining monetary input and output data.

EU KLEMS, however, does not contain capital stock data for sector 40x of the NACE 1.1 classification (the electricity sector) but only for the more aggregate sector E. But, it contains capital compensation data of sector 40x. We use the capital compensation data to approximate the capital stock of sector 40x by assuming that the capital compensation per unit of capital is identical for all of the subsectors of sector E. This requires the assumption of identical capital structures in the electricity, gas and water supply industries, what might be not too misleading given their overall similarity. Monetary variables are deflated

\footnotetext{
${ }^{6}$ These values represent assumptions used in the Electricity Market Module of the Annual Energy Outlook, http://www.eia.gov/oiaf/archive.html.
} 
and converted into dollar using price indices and PPPs from sector E (see next section for details on the use of PPPs). Table 2 summarizes the variables available. The data set exhibits up to 390 observations (15 years and 26 countries).

\section{$5.2 \quad$ Non-Energy Industries}

Three steps are undertaken to construct the data for the non-energy sector from the WIOD and the GGDC Productivity Level Database. First, energy use by fuel type is aggregated into a clean and a dirty aggregate. In doing so, we are adding up biogasoline, biodiesel, biogas, other renewables, electricity, heat production, hydro, geothermal, solar, wind, other sources, nuclear and waste into a clean aggregate. All other types of energy generating technologies sum up to the dirty aggregate. The second step deals with the construction of intermediate energy, services and materials input aggregates. These are not given in WIOD directly but can be derived from its Use tables. Following the EU KLEMS methodology (Timmer et al., 2007), energy intermediate inputs (IIE) are defined as all energy mining products (produced by sector 10-12), oil refining products (23) as well as electricity and gas products (40) that are used as intermediate production inputs. Intermediate service inputs (IIS) are defined as all service products used (50-99), whereas all remaining products are classified as intermediate materials inputs (IIM). This classification can be applied one to one to the WIOD Use tables at purchasers prices. ${ }^{7}$ In a third step, the nominal values in local currency are transformed into real values of a common currency (in our case real 1997 US\$). This requires using the PPPs from the GGDC Productivity Level Database in combination with price indices from WIOD. ${ }^{8}$ This is done through a two-step procedure which uses the PPP values, $P P P_{k, i, 1997}$, and the price indices, $P_{k, i, t}$, for gross output (GO), value added (VA), intermediate inputs (II) and

\footnotetext{
${ }^{7}$ Comparing the IIE, IIS and IIM values which we obtain through this procedure with the IIE, IIS and IIM values given in the EU KLEMS database from 2008 shows rather small differences, which are also present in total intermediate or value added numbers that exist in both databases. However, since the EU KLEMS database exhibits values for IIE, IIS and IIM only in its first version and only covers a limited number of countries we decided to stick to the data derived from WIOD.

${ }^{8}$ The two databases, WIOD and GGDC, exhibit small differences in their industry coverage. WIOD contains data for the industries $17 \mathrm{t} 18,19,50,51,52,60,61,62$ and 63 , whereas the GGDC database contains PPPs for three aggregates of these nine industries (17t19, G and 60t63). To cope with this, two options are at hand, either the WIOD industry data are aggregated and then matched with the GGDC values or the aggregate PPP values are directly used for their subsectors. The second approach allows to maximize the number of observations, however, it requires assuming the validity of using aggregate PPPs directly for subsectors. Here, the second approach is chosen since we believe that the measurement error introduced by this assumption can be neglected.
} 
Variable Description and Unit of Measurement

Gross output at real 1997 US dollar (PPP)

Gross value added at real 1997 US dollar (PPP)

Intermediate energy input at real 1997 US dollar (PPP)

Intermediate materials and service input at real 1997 US dollar (PPP)

Real fixed capital stock at real 1997 US dollar (PPP)

Total hours worked by persons engaged

Energy use of clean sources (in TJ)

Energy use of dirty sources (in TJ)

the capital stock $(\mathrm{K})$. Technically, the conversion factors, $P P P_{k, i, t}$, are derived by

$$
P P P_{k, i, t}=\frac{P_{k, i, 1997}}{P_{k, i, t}} \frac{1}{P P P_{k, i, 1997}}
$$

where $k \in\{\mathrm{GO}, \mathrm{VA}, \mathrm{II}, \mathrm{K}\}, i$ stands for the country industry combinations available and $t$ denotes time. Multiplying the nominal values with these conversion factors then yields real values. In this procedure, the $P P P_{G O, i, t}$ are used to convert the gross output time-series, the $P P P_{V A, i, t}$ are used to convert the value added time-series, the $P P P_{I I, i, t}$ are used to convert all intermediate input time-series and the $P P P_{K, i, t}$ are applied to convert the real fixed capital stock data.

In combination, these three steps lead to a data set containing the variables necessary for our analysis. They are summarized in Table 3. The part of our data set relevant for the analysis of the non-energy sector then contains observations for 19 countries (AUS, AUT, BEL, CZE, DEU, DNK, ESP, FIN, FRA, GBR, HUN, IRL, ITA, JPN, NLD, PRT, SVN, SWE, USA), 28 industries (see Table 10) and the time between 1995 and 2007, resulting in a nearly balanced panel of 6914 observations. $^{9}$

\footnotetext{
${ }^{9}$ We drop observations of Luxembourg, because of several extreme values, as well as the industries 'wood and of products of wood and cork' (20), 'coke, refined petroleum and nuclear fuel' (23), 'other water transport' (61), 'other air transport' (62) and 'real estate activities' (70). Industries 61 and 62 are neglected since nearly no observations are available for them in the raw data. Industries 20, 23 and 70 show extreme ratios of clean to dirty energy use, thereby picking up energy use which is not relevant to our analysis (e.g usage of wood as a raw material in the production of furniture).
} 


\section{$6 \quad$ Results}

\subsection{Electricity Sector}

We estimate the CES function (Equation 3) for the electricity-generating sector, first using nonlinear least squares (first two columns of Table 4), then using the linear Kmenta approximation (third and fourth column of Table 4). Both variants are estimated first with country dummies and then in first differences in order to account for heterogeneity across countries. Output is measured as electricity generation (GWh), inputs are measured as (clean and dirty) installed generation capacity (MW).

Nonlinear estimation reported in this and in the next section relies on nonlinear optimization methods to search for the parameter values that minimize the residual sum of squares and to estimate the confidence intervals of these estimates. A parameter space that often exhibits multimodality and flat regions for the CES function is known to complicate estimation (León-Ledesma, McAdam, and Willman 2010b). The function is nonlinear in $\psi$, which appears as an exponent, and $\psi$ is in turn nonlinear in $\sigma_{C D}$. To reduce the extent of nonlinearity, we perform estimation and tests on $\psi$. Standard errors are bootstrapped with clusters at the country (and if applicable industry) level. Degenerate results where the numerical search either does not converge or finds a $\psi$ larger than one are discarded from the bootstrap. Around $\psi=1$, the elasticity of substitution jumps from plus infinity to minus infinity.

For the electricity generating sector, we obtain estimates of the substitution parameter $\psi$ of around 0.46 which are significantly different from zero. A value of zero would imply a unitary elasticity of substitution. The estimates imply an elasticity of substitution between clean and dirty energy inputs of about 1.8. This would place us in a case where long-term clean growth of the electricity sector is technologically feasible. In the context of the model of AABH (which, however, makes different assumptions on technical progress) this would be on the edge of a situation with or without rebound effects of clean innovation.

In Table 5 we use approximated real capital stocks instead of capacities in MW as input measures. The estimates of the elasticity of substitution change only little. The scope of the sensitivity analysis possible is, however, limited by the lack of plant cost data across fuels used, countries and time. 
Finally, we relax the assumption of a two-factor CES function which implicitly assumes fixed proportions of all other inputs. The Cobb-Douglas-in-CES specification (Equation 4) allows for substitution between dirty capacity and dirty fuels assuming a unitary elasticity. With this specification, the estimate of the elasticity of substitution between clean and dirty electricity generation rises to values above two (Table 6). The estimate of the distribution parameter $\omega$ becomes more instable across specifications.

Table 4: Nonlinear Estimation and Kmenta Approximation of CES - Electricity Sector

\begin{tabular}{lccccc}
\hline \hline & \multicolumn{2}{c}{ CES } & & \multicolumn{2}{c}{ Kmenta } \\
\cline { 2 - 3 } \cline { 5 - 6 } & NLS & FD NLS & & OLS & FD OLS \\
\hline $\mathrm{d}$ & -0.001 & -0.003 & & -0.001 & -0.003 \\
& $(-0.67)$ & $(-1.57)$ & & $(-0.50)$ & $(-1.18)$ \\
$\omega$ & $0.220^{* *}$ & $0.442^{* * *}$ & & $0.245^{* * *}$ & $0.451^{* * *}$ \\
& $(2.44)$ & $(5.80)$ & & $(6.02)$ & $(7.87)$ \\
$\psi$ & $0.457^{* *}$ & $0.487^{* * *}$ & & $0.446^{* * *}$ & $0.455^{* * *}$ \\
& $(2.09)$ & $(3.65)$ & & $(3.39)$ & $(9.87)$ \\
\hline Country DV & Yes & No & & Yes & No \\
adj. $R^{2}$ & 0.997 & 0.187 & & 0.968 & 0.546 \\
$\psi=0$ & 0.037 & 0.000 & & 0.002 & 0.000 \\
$\sigma_{C D}$ & 1.840 & 1.948 & & 1.806 & 1.833 \\
$N$ & 390 & 364 & 390 & 364 \\
\hline \hline
\end{tabular}

Notes: z-statistics in parentheses. ***, **, *: Significantly different from 0 at the 1\%, 5\%, and 10\% levels, respectively. Column 1 and 2 provide bootstrapped standard errors based on 400 replications with country as cluster variable. Specification 1 applies the Nonlinear Least Squares (NLS) estimator and includes country dummies. Specification 2 applies the NLS estimator to a first differenced version of the model. Specification 3 applies the OLS estimator and includes country dummies. Specification 4 applies the OLS estimator to a first differenced version of the model. $\psi=0$ reports the significance level of a Wald test with $H_{0}: \psi=0$. 
Table 5: Nonlinear Estimation and Kmenta Approximation of CES with an Alternative Capital Proxy - Electricity Sector

\begin{tabular}{lccccc}
\hline \hline & \multicolumn{2}{c}{ CES } & & \multicolumn{2}{c}{ Kmenta } \\
\cline { 2 - 3 } \cline { 5 - 6 } & NLS & FD NLS & & OLS & FD OLS \\
\hline $\mathrm{d}$ & $-0.010^{* * *}$ & $-0.009^{* * *}$ & & $-0.009^{* * *}$ & $-0.009^{* * *}$ \\
& $(-3.67)$ & $(-3.92)$ & & $(-3.97)$ & $(-3.35)$ \\
$\omega$ & $0.193^{*}$ & $0.388^{* * *}$ & & $0.203^{* * *}$ & $0.401^{* * *}$ \\
& $(1.68)$ & $(3.57)$ & & $(4.01)$ & $(6.39)$ \\
$\psi$ & $0.423^{*}$ & $0.460^{* * *}$ & & $0.535^{* * *}$ & $0.441^{* * *}$ \\
& $(1.70)$ & $(2.59)$ & & $(2.74)$ & $(5.17)$ \\
\hline Country DV & Yes & No & & Yes & No \\
adj. $R^{2}$ & 0.997 & 0.053 & & 0.965 & 0.555 \\
$\psi=0$ & 0.090 & 0.010 & & 0.011 & 0.000 \\
$\sigma_{C D}$ & 1.734 & 1.852 & & 2.152 & 1.789 \\
$N$ & 338 & 312 & & 338 & 312 \\
\hline \hline
\end{tabular}

Notes: z-statistics in parentheses. ${ }^{* * *},{ }^{* *},{ }^{*}$ : Significantly different from 0 at the $1 \%, 5 \%$, and $10 \%$ levels, respectively. Column 1 and 2 provide bootstrapped standard errors based on 400 replications with country as cluster variable. Specification 1 applies the Nonlinear Least Squares (NLS) estimator and includes country dummies. Specification 2 applies the NLS estimator to a first differenced version of the model. Specification 3 applies the OLS estimator and includes country dummies. Specification 4 applies the OLS estimator to a first differenced version of the model. $\psi=0$ reports the significance level of a Wald test with $H_{0}: \psi=0$. 
Table 6: Nonlinear Estimation of Cobb-Douglas in CES - Electricity Sector

\begin{tabular}{lccccc}
\hline \hline & \multicolumn{2}{c}{ Main Capital Proxy } & & \multicolumn{2}{c}{ Alternative Capital Proxy } \\
\cline { 2 - 3 } \cline { 5 - 6 } & NLS & FD NLS & & NLS & FD NLS \\
\hline \multirow{2}{*}{$\mathrm{d}$} & 0.003 & 0.003 & & -0.000 & -0.000 \\
& $(1.47)$ & $(1.34)$ & & $(-0.19)$ & $(-0.10)$ \\
$\alpha$ & $0.437^{* * *}$ & $0.379^{* * *}$ & & $0.347^{* * *}$ & $0.311^{* * *}$ \\
& $(6.33)$ & $(4.03)$ & & $(5.72)$ & $(3.60)$ \\
$\omega$ & $0.488^{* * *}$ & $0.707^{* * *}$ & & 0.010 & 0.005 \\
& $(4.83)$ & $(10.08)$ & & $(0.14)$ & $(0.37)$ \\
$\psi$ & $0.508^{* * *}$ & $0.651^{* * *}$ & & $0.508^{* * *}$ & $0.644^{* * *}$ \\
& $(3.30)$ & $(4.53)$ & & $(3.31)$ & $(4.83)$ \\
\hline \multirow{2}{*}{ Country DV } & Yes & No & & Yes & No \\
adj. $R^{2}$ & 0.999 & 0.525 & & 0.999 & 0.500 \\
$\psi=0$ & 0.001 & 0.000 & & 0.001 & 0.000 \\
$\sigma_{C D}$ & 2.031 & 2.867 & & 2.034 & 312 \\
$N$ & 390 & 364 & 338 & 310 \\
\hline \hline
\end{tabular}

Notes: z-statistics in parentheses. ${ }^{* * *},{ }^{* *}, *$ : Significantly different from 0 at the $1 \%, 5 \%$, and $10 \%$ levels, respectively. All columns provide bootstrapped standard errors based on 400 replications with country as cluster variable. Specification 1 and 3 apply the Nonlinear Least Squares (NLS) estimator and include country dummies. Specification 2 and 4 apply the NLS estimator to a first differenced version of the model. $\psi=0$ reports the significance level of a Wald test with $H_{0}: \psi=0$. 


\subsection{Non-Energy Industries}

The main specification we employ for non-energy industries is a production function that is CES in clean and dirty fuel input and Cobb-Douglas in the energy aggregate and other inputs (Equation 5). The function is estimated using nonlinear least squares (first two columns of Table 7) and the linear Kmenta approximation (third and fourth column of Table 7) using dummy variables for countries and industries. As discussed in Section 4.2.2, we use two alternative dependent variables, gross output and value added plus intermediate energy input.

The estimates for the substitution parameter $\psi$ are significantly positive in all specifications except the Kmenta approximation for gross output. As an approximation around $\psi=0$ the Kmenta approximation is known to bias elasticity parameters of CES functions downwards. One reason why we observe a larger difference in the estimates between nonlinear and Kmenta estimation than we did for the electricity sector may be that the data for different industries exhibit higher dispersion.

So far we have assumed a unitary elasticity of substitution between energy and nonenergy inputs. Since a large literature, most recently Hassler, Krusell, and Olovsson (2012), finds evidence of a lower elasticity, we also estimate a more general two-level CES specification (see Equation 6), where only the aggregate of capital, labor and non-energy intermediates remain in a Cobb-Douglas structure and substitution between energy and non-energy aggregates can assume any value. Looking at the results in Table 8, it turns out that identifying two elasticities in a highly nonlinear function becomes difficult. The elasticity of substitution between energy and non-energy inputs estimated with augmented value added as dependent variable does not differ significantly from one (i.e., $\phi$ does not differ from zero). With gross output as dependent variable, we observe implausible parameter estimates: a negative elasticity of substitution between clean and dirty energy inputs and a distribution parameter $\zeta$ of non-energy input close to zero. 
Table 7: Nonlinear Estimation and Kmenta Approximation of CES in Cobb-Douglas Non-Energy Industries

\begin{tabular}{lccccc}
\hline \hline & \multicolumn{2}{c}{ CES in Cobb-Douglas } & & \multicolumn{2}{c}{ Kmenta } \\
\cline { 2 - 3 } \cline { 5 - 6 } & VA + IIE & GO & & VA + IIE & GO \\
\hline $\mathrm{d}$ & $0.010^{* * *}$ & $0.003^{*}$ & & $0.010^{* * *}$ & $0.002^{*}$ \\
& $(4.66)$ & $(1.82)$ & & $(4.79)$ & $(1.73)$ \\
$\alpha$ & $0.359^{* * *}$ & $0.186^{* * *}$ & & $0.360^{* * *}$ & $0.187^{* * *}$ \\
& $(7.45)$ & $(6.65)$ & & $(7.78)$ & $(7.04)$ \\
$\gamma$ & $0.260^{* * *}$ & $0.121^{* * *}$ & & $0.258^{* * *}$ & $0.121^{* * *}$ \\
& $(6.23)$ & $(5.10)$ & & $(6.15)$ & $(4.88)$ \\
$\theta$ & & & & & $0.566^{* * *}$ \\
& & & & & $(16.54)$ \\
$\psi$ & $0.651^{* * *}$ & $0.654^{* *}$ & & $0.394^{* * *}$ & 0.276 \\
& $(3.28)$ & $(2.27)$ & & $(2.97)$ & $(1.41)$ \\
\hline Country DV & Yes & Yes & & Yes & Yes \\
Industry DV & Yes & Yes & & Yes & Yes \\
$\psi=0$ & 0.001 & 0.023 & & 0.003 & 0.159 \\
$\sigma_{C D}$ & 2.868 & 2.888 & & 1.651 & 1.382 \\
adj. $R^{2}$ & 0.948 & 0.982 & 0.739 & 0.907 \\
$N$ & 6914 & 6914 & 6914 & 6914 \\
\hline \hline
\end{tabular}

Notes: z-statistics in parentheses. ${ }^{* * *},{ }^{* *},{ }^{*}$ : Significantly different from 0 at the $1 \%, 5 \%$, and $10 \%$ levels, respectively. Columns 1 and 2 provide bootstrapped standard errors based on 400 replications with country and industry as cluster variables. Specification 1 and 2 apply the Nonlinear Least Squares (NLS) estimator and include country and industry dummy variables. Specification 3 and 4 apply the OLS estimator and include country and industry dummy variables. $\psi=0$ reports the significance level of a Wald test with $H_{0}: \psi=0$. 
Table 8: Nonlinear Estimation of Two-level CES - Non-Energy Industries

\begin{tabular}{|c|c|c|}
\hline & \multicolumn{2}{|c|}{ Two-level CES } \\
\hline & $\mathrm{VA}+\mathrm{IIE}$ & GO \\
\hline $\mathrm{d}$ & $\begin{array}{c}0.010^{* * *} \\
(4.14)\end{array}$ & $\begin{array}{c}0.003^{* *} \\
(2.37)\end{array}$ \\
\hline$\alpha$ & $\begin{array}{c}0.474^{* * *} \\
(6.14)\end{array}$ & $\begin{array}{c}0.191^{* * *} \\
(6.88)\end{array}$ \\
\hline$\theta$ & & $\begin{array}{c}0.618^{* * *} \\
(18.37)\end{array}$ \\
\hline$\zeta$ & $\begin{array}{c}0.679^{* * *} \\
(3.21)\end{array}$ & $\begin{array}{l}0.011 \\
(0.40)\end{array}$ \\
\hline$\phi$ & $\begin{array}{l}0.076 \\
(0.25)\end{array}$ & $\begin{array}{c}0.744^{* *} \\
(2.49)\end{array}$ \\
\hline$\psi$ & $\begin{array}{c}0.683^{* * *} \\
(3.12)\end{array}$ & $\begin{array}{l}1.477 \\
(1.03)\end{array}$ \\
\hline Country DV & Yes & Yes \\
\hline Industry DV & Yes & Yes \\
\hline$\phi=0$ & 0.801 & 0.013 \\
\hline$\psi=0$ & 0.002 & 0.304 \\
\hline$\sigma_{K L E}$ & 1.082 & 3.908 \\
\hline$\sigma_{C D}$ & 3.153 & -2.095 \\
\hline $\operatorname{adj} . R^{2}$ & 0.948 & 0.982 \\
\hline$N$ & 6914 & 6914 \\
\hline
\end{tabular}

Notes: z-statistics in parentheses. ${ }^{* * *},{ }^{* *}, *$ : Significantly different from 0 at the $1 \%, 5 \%$, and $10 \%$ levels, respectively. Column 1 provides bootstrapped standard errors based on 400 replications with country and industry as cluster variables. Specification 1 and 2 apply the Nonlinear Least Squares (NLS) estimator and include country and industry dummy variables. $\psi=0$ reports the significance level of a Wald test with $H_{0}: \psi=0 . \phi=0$ reports the significance level of a Wald test with $H_{0}: \phi=0$. 


\subsection{Discussion}

Our results support the assumption that the elasticity of substitution between clean and dirty energy inputs exceeds the value of one significantly, both in the electricity generating sector and in the non-energy industries. In Section 3.2 we showed conditions under which the economy-wide elasticity would be a weighted average of these values. Given the estimates, the economy-wide elasticity can also be expected to exceed the value of one, possibly even two. We discussed in Section 3.2 that we consider it to be plausible that the more general elasticity of substitution, the one between clean and dirty production, is not much lower than the one we have estimated. Still, we do not find evidence of an extremely high elasticity (around ten) that is necessary for the most optimistic scenario in the simulations by AABH. We suspect that the difference between a high and a very high elasticity of substitution mostly matters for the anticipated long-run outcomes. It would be hazardous to make a long-run prediction about the elasticity of substitution between clean and dirty energy inputs from our estimates.

With the available data, we face some econometric limitations: Instrumenting endogenous inputs with internal instruments proved difficult, since test statistics generally indicated that the instruments were not exogenous. We therefore do not report results with these methods. Moreover, with 13 to 15 observations per entity we are in a case that is not favorable to study cointegration or to use heterogenous (dynamic) panel data models.

Given the remaining uncertainty, on both the theoretical and the econometric status of our results, what insight do we gain from them? In neoclassical production theory the crucial threshold for factor substitution are unitary elasticities, meaning that above or below this value the main model predictions with regard to growth, distribution and technical change in the long-run are completely inverted. Our estimates provide first econometric evidence that elasticities above one are much more plausible than informed guesses based on the previous literature on interfuel substitution suggest.

Why are our results so different? We consider one reason to be that we do not assume equality of marginal productivity of energy and energy prices at the macroeconomic level. For comparison, we additionally estimate the elasticity of substitution between clean and 
dirty energy inputs for non-energy industries using first-order conditions. The sample with added price data is described in the Appendix. We choose the most parsimonious specification possible, exploiting the fact that the separability of the production function allows to estimate elasticities from the energy submodel only (Fuss 1977). Taking the firstorder conditions for clean and dirty energy inputs from the production function (Equation 5) and rearranging yields the following system of equations:

$$
\begin{aligned}
& \ln \left(\frac{p_{C i t} E_{C i t}}{p_{C i t} E_{C i t}+p_{D i t} E_{D i t}}\right)=\left(1-\sigma_{C D}\right) \ln \left(\frac{p_{C i t}}{p_{E i t}}\right)+\varepsilon_{i t} \\
& \ln \left(\frac{p_{D i t} E_{D i t}}{p_{C i t} E_{C i t}+p_{D i t} E_{D i t}}\right)=\left(1-\sigma_{C D}\right) \ln \left(\frac{p_{D i t}}{p_{E i t}}\right)+\nu_{i t} .
\end{aligned}
$$

We estimate these equations using seemingly unrelated regression (SUR), first in the above form that directly follows from the function used in the previous section and then adding a time trend and dummies for countries and industries. These dummies would reflect heterogenous parameters and nonneutral technological progress that we did not attempt to identify without the linear first-order conditions. In the first column of Table 9, we obtain a value of 0.43 for the elasticity of substitution that comes surprisingly close to the value found by Pelli (2012) using price data (analyzing the electricity sector only) and put forward by Hourcade, Pottier, and Espagne (2011) based on previous literature. Adding controls, the elasticity becomes negative, which is implausible in neoclassical production theory but not uncommon in the earlier literature estimating partial elasticities between fuels. 
Table 9: CES for Energy Subaggregate Price Based SUR Estimation - Non-Energy Industries

\begin{tabular}{lccc}
\hline \hline & \multicolumn{3}{c}{ CES for Energy Subaggregate } \\
\cline { 2 - 4 } & $(1)$ & $(2)$ & $(3)$ \\
\hline$d_{1}$ & & $-0.001^{* * *}$ & $-0.001^{* * *}$ \\
& & $(-28.53)$ & $(-7.54)$ \\
$d_{2}$ & & $-0.000^{* * *}$ & $-0.000^{* * *}$ \\
& & $(-18.19)$ & $(-6.31)$ \\
$\sigma_{C D}$ & $0.433^{* * *}$ & -0.099 & -0.002 \\
& $(5.63)$ & $(-1.32)$ & $(-0.02)$ \\
\hline \multirow{2}{*}{ Country DV } & No & No & Yes \\
Industry DV & No & No & Yes \\
& 3220 & 3220 & 3220 \\
\hline \hline
\end{tabular}

Notes: Heteroscedasticity- and autocorrelation-robust z-statistics in parentheses. ${ }^{* * *},{ }^{* *},{ }^{*}$ :

Significantly different from 0 at the $1 \%, 5 \%$, and $10 \%$ levels, respectively. Specification 1 to 3 apply the Feasible Generalized Nonlinear Least Squares (FGNLS) estimator to the system of equations.

Specification 2 and 3 include equation specific time trends. Specification 3 includes equation specific country and industry dummies.

\section{Conclusion}

In the context of growth models with neoclassical production functions, the elasticity of substitution between clean and dirty production represents a central parameter when it comes to assess the conditions for long-run green growth. In this paper we produce first econometric evidence on a special case of this elasticity, the elasticity between clean and dirty energy inputs. Our contribution is threefold: First, we provide a simple argument in the context of production theory how the aggregate elasticity of substitution between clean and dirty inputs depends on the elasticities in the energy-producing and the energyusing sector. This leads us to formulate parsimonious CES-type production functions that can be used for econometric analysis. Second, we use novel data sources, in particular the World-Input-Output-Database (WIOD), to construct panel data at the industry level covering clean and dirty inputs in addition to the standard variables of productivity analysis. Third, we present evidence that the aggregate elasticity of substitution between clean and dirty energy inputs exceeds unity. This result sharply contrasts with expectations that researchers had formulated based on the earlier literature on interfuel substitution which relies on the use of price data. 
The data and specifications we put together also give rise to ideas how to evaluate the elasticity of substitution between clean and dirty production in a more nuanced way than we could in this first attempt from a macroeconomic perspective. Some of these steps may well challenge the results we have found, but we nevertheless consider our parsimonious specification as a useful point of reference. A potential avenue for a more precise estimation of substitution possibilities in the electricity generating sector could be to directly work with plant level data. Instead of using a binary distinction between clean and dirty fuels, future research on non-energy industries could use fuel-specific data on actual emissions and develop a specification of the technology that accounts for an unwanted output. This would allow to account in a more exact way for the fact that not all energy inputs causing emissions are equally dirty. 


\section{References}

Acemoglu, D., P. Aghion, L. Bursztyn, and D. Hemous (2012): "The Environment and Directed Technical Change," American Economic Review, 102(1), 131-166.

Acemoglu, D., P. Aghion, And D. Hemous (2013): "The Environment and Directed Technical Change in a North-South Model," mimeo.

Aghion, P., A. Dechezleprêtre, D. Hemous, R. Martin, and J. Van Reenen (2012): "Carbon Taxes, Path Dependency and Directed Technical Change: Evidence from the Auto Industry," NBER Working Paper Series 18596.

Aghion, P., And P. Howitt (1998): Endogenous Growth Theory. MIT Press.

Atkinson, S., And R. Halvorsen (1976): "Interfuel Substitution in Steam Electric Power Generation," Journal of Political Economy, 84(5), 959-978.

Berndt, E., And D. Wood (1975): "Technology, Prices, and the Derived Demand for Energy," Review of Economics and Statistics, 57(3), 259-268.

Bopp, A., And D. Costello (1990): "The Economics of Fuel Choice at US Electric Utilities," Energy Economics, 12(2), 82-88.

Bretschger, L., AND S. Smulders (2012): "Sustainability and Substitution of Exhaustible Natural Resources: How Structural Change Affects Long-Term R\&DInvestments," Journal of Economic Dynamics and Control, 36(4), 536-549.

Considine, T. (1989): "Separability, Functional Form and Regulatory Policy in Models of Interfuel Substitution," Energy Economics, 11(2), 82-94.

Considine, T., And D. Larson (2009): "Substitution and Technological Change Under Carbon Cap and Trade: Lessons from Europe," World Bank Policy Research Working Paper 4957.

Dhrymes, P., And M. Kurz (1964): "Technology and Scale in Electricity Generation," Econometrica, 32(3), 287-315. 
Dietzenbacher, E., B. Los, R. Stehrer, M. Timmer, and G. De Vries (2013): "The Construction of World Input-Output Tables in the WIOD Project," Economic Systems Research, 25(1), 71-98.

FÄre, R., S. Grosskopf, D. Noh, and W. Weber (2005): "Characteristics of a Polluting Technology: Theory and Practice," Journal of Econometrics, 126(2), 469492.

Frondel, M. (2010): "Substitution Elasticities: A Theoretical and Empirical Comparison," SFB 823 Discussion Paper 33/2010.

Frondel, M., And C. Schmidt (2006): "The Empirical Assessment of Technology Differences: Comparing the Comparable," Review of Economics and Statistics, 88(1), $186-192$.

Fuss, M. (1977): "The Demand for Energy in Canadian Manufacturing: An Example of the Estimation of Production Structures with Many Inputs," Journal of Econometrics, $5(1), 89-116$.

Griffin, J. (1977): "Interfuel Substitution Possibilities: a Translog Application to Intercountry Data," International Economic Review, 18(3), 755-770.

Griffin, J., And P. Gregory (1976): "An Intercountry Translog Model of Energy Substitution Responses," American Economic Review, 66(5), 845-857.

Hassler, J., P. Krusell, and C. Olovsson (2012): "Energy-Saving Technical Change," NBER Working Paper Series 18456.

Heutel, G., And C. Fischer (2013): "Environmental Macroeconomics: Environmental Policy, Business Cycles, and Directed Technical Change," NBER Working Paper Series 18794.

Hourcade, J., A. Pottier, and E. Espagne (2011): "The Environment and Directed Technical Change: Comment," FEEM Working Paper 2011.095.

IEA / OECD (2013): Electricity Information 2013. OECD Publishing. 
IEA/ OECD NEA (2010): Projected Costs of Generating Electricity 2010. OECD Publishing, Paris.

InklaAR, R., And M. Timmer (2008): "GGDC Productivity Level Database: International Comparisons of Output, Inputs and Productivity at the Industry Level," GGDC Research Memorandum.

Jones, C. (1995): “A Dynamic Analysis of Interfuel Substitution in US Industrial Energy Demand," Journal of Business $\&$ Economic Statistics, 13(4), 459-465.

Jones, R. W. (1965): "The Structure of Simple General Equilibrium Models," Journal of Political Economy, 73(6), 557-572.

Kemfert, C. (1998): "Estimated Substitution Elasticities of a Nested CES Production Function Approach for Germany," Energy Economics, 20(3), 249-264.

Kmenta, J. (1967): "On Estimation of the CES Production Function," International Economic Review, 8(2), 180-189.

Koetse, M., H. De Groot, and R. Florax (2008): "Capital-Energy Substitution and Shifts in Factor Demand: A Meta-Analysis," Energy Economics, 30(5), 2236-2251.

Lanzi, E., And I. Sue Wing (2010): "Directed Technical Change in the Energy Sector: An Empirical Test of Induced Directed Innovation," Paper presented at the SURED Conference, ETH Zurich.

León-Ledesma, M. A., P. McAdam, and A. Willman (2010a): "Identifying the Elasticity of Substitution with Biased Technical Change," American Economic Review, 100(4), 1330-1357.

(2010b): "In Dubio Pro CES: Supply Estimation with Misspecified TechnicalChange," Working Paper 1175, European Central Bank.

Mattauch, L., F. Creutzig, and O. Edenhofer (2012): "Avoiding Carbon Lock-In: Policy Options for Advancing Structural Change," Climatecon Working Paper 1/2012.

Miyagiwa, K., And C. Papageorgiou (2007): "Endogenous Aggregate Elasticity of Substitution," Journal of Economic Dynamics and Control, 31(9), 2899-2919. 
Papageorgiou, C., And M. SaAm (2008): "Two-level CES Production Technology in the Solow and Diamond Growth Models," Scandinavian Journal of Economics, 110(1), $119-143$.

Pelli, M. (2012): "The Elasticity of Substitution between Clean and Dirty Inputs in the Production of Electricity," Discussion paper, Universita della Svizzera Italiana.

Pettersson, F., P. Söderholm, and R. Lundmark (2012): "Fuel Switching and Climate and Energy Policies in the European Power Generation Sector: A Generalized Leontief Model," Energy Economics, 34(4), 1064-1073.

Pindyck, R. (1979): "Interfuel Substitution and the Industrial Demand for Energy: An International Comparison," Review of Economics and Statistics, 61(2), 169-179.

Popp, D., R. Newell, and A. Jaffe (2010): "Energy, the Environment, and Technological Change," in Handbook of the Economics of Innovation 2, ed. by B. Hall, and N. Rosenberg, chap. 21, pp. 873-937. Elsevier, Amsterdam.

Revankar, N. S. (1971): "A Class of Variable Elasticity of Substitution Production Functions," Econometrica: Journal of the Econometric Society, 39(1), 61-71.

Serletis, A., G. Timilsina, and O. Vasetsky (2011): "International Evidence on Aggregate Short-Run and Long-Run Interfuel Substitution," Energy Economics, 33(2), 209-216.

Söderholm, P. (2001): "Fossil Fuel Flexibility in West European Power Generation and the Impact of System Load Factors," Energy Economics, 23(1), 77-97.

Steinbuks, J. (2010): "Interfuel Substitution and Energy Use in the UK Manufacturing Sector," Cambridge Working Papers Series in Economics 1032.

Stern, D. I. (2012): "Interfuel Substitution: A Meta-Analysis," Journal of Economic Surveys, 26(2), 307-331.

Stokey, N. L. (1996): "Free Trade, Factor Returns, and Factor Accumulation," Journal of Economic Growth, 1(4), 421-447. 
TAYlor, T., And P. Thompson (1995): "The Capital-Energy Substitutability Debate: A New Look," Review of Economics and Statistics, 77(3), 565-569.

Timmer, M. P. (2012): "The World Input-Output Database (WIOD): Contents, Sources and Methods," WIOD working paper no. 10, available at www.wiod.org/publications/papers/wiod10.pdf.

VAN DeR Werf, E. (2008): "Production Functions for Climate Policy Modeling: An Empirical Analysis," Energy Economics, 30(6), 2964-2979. 


\section{Appendix}

\subsection{Sectoral Coverage of the Data}

Table 10: Sectoral Coverage

\begin{tabular}{|c|c|c|c|c|c|c|}
\hline Sector & Code & WIOD & GGDC & KLEMS & IEA & Sample \\
\hline Total industries & TOT & $\mathrm{x}$ & $\mathrm{x}$ & & & \\
\hline Agriculture, hunting, forest, fish. & AtB & $\mathrm{x}$ & $\mathrm{x}$ & & & 1 \\
\hline Mining and quarrying & $\mathrm{C}$ & $\mathrm{x}$ & $\mathrm{x}$ & & & 1 \\
\hline Food, beverages and tobacco & $15 \mathrm{t} 16$ & $\mathrm{x}$ & $\mathrm{x}$ & & & 1 \\
\hline Textiles, textile, leather and footwear & $17 \mathrm{t} 19$ & & $\mathrm{x}$ & & & \\
\hline Textiles and textile & $17 \mathrm{t} 18$ & $\mathrm{x}$ & & & & 1 \\
\hline Leather, leather and footwear & 19 & $\mathrm{x}$ & & & & 1 \\
\hline Wood and of wood and cork & 20 & $\mathrm{x}$ & $\mathrm{x}$ & & & \\
\hline Pulp, paper, printing and publishing & $21 \mathrm{t} 22$ & $\mathrm{x}$ & $\mathrm{x}$ & & & 1 \\
\hline $\begin{array}{l}\text { Coke, refined petroleum and nuclear } \\
\text { fuel }\end{array}$ & 23 & $\mathrm{x}$ & $\mathrm{x}$ & & & \\
\hline Chemicals and chemical & 24 & $\mathrm{x}$ & $\mathrm{x}$ & & & 1 \\
\hline Rubber and plastics & 25 & $\mathrm{x}$ & $\mathrm{x}$ & & & 1 \\
\hline Other non-metallic mineral & 26 & $\mathrm{x}$ & $\mathrm{x}$ & & & 1 \\
\hline Basic metals and fabricated metal & $27 \mathrm{t} 28$ & $\mathrm{x}$ & $\mathrm{x}$ & & & 1 \\
\hline Machinery, nec & 29 & $\mathrm{x}$ & $\mathrm{x}$ & & & 1 \\
\hline Electrical and optical equipment & $30 \mathrm{t} 33$ & $\mathrm{x}$ & $\mathrm{x}$ & & & 1 \\
\hline Transport equipment & $34 \mathrm{t} 35$ & $\mathrm{x}$ & $\mathrm{x}$ & & & 1 \\
\hline Manufacturing nec; recycling & $36 \mathrm{t} 37$ & $\mathrm{x}$ & $\mathrm{x}$ & & & 1 \\
\hline Electricity, gas and water supply & $\mathrm{E}$ & $\mathrm{x}$ & $\mathrm{x}$ & & & \\
\hline Electricity and gas & 40 & & & $\mathrm{x}$ & $\mathrm{x}$ & \\
\hline Electricity supply & $40 \mathrm{x}$ & & & $\mathrm{x}$ & $\mathrm{x}$ & 2 \\
\hline Gas supply & 402 & & & $\mathrm{x}$ & $\mathrm{x}$ & \\
\hline Wholesale trade and commission trade & 51 & $\mathrm{x}$ & & & & 1 \\
\hline Retail trade, except of motor vehicles; & 52 & $\mathrm{x}$ & & & & 1 \\
\hline Hotels and restaurants & $\mathrm{H}$ & $\mathrm{x}$ & $\mathrm{x}$ & & & 1 \\
\hline Transport and storage & $60 t 63$ & & $\mathrm{x}$ & & & \\
\hline Other Inland transport & 60 & $\mathrm{x}$ & & & & 1 \\
\hline Other Water transport & 61 & $\mathrm{x}$ & & & & \\
\hline Other Air transport & 62 & $\mathrm{x}$ & & & & \\
\hline $\begin{array}{l}\text { Other Supporting and auxil. transp. } \\
\text { act. }\end{array}$ & 63 & $\mathrm{x}$ & & & & 1 \\
\hline Post and telecommunications & 64 & $\mathrm{x}$ & $\mathrm{x}$ & & & 1 \\
\hline Financial intermediation & $\mathrm{J}$ & $\mathrm{x}$ & $\mathrm{x}$ & & & 1 \\
\hline Real estate activities & 70 & $\mathrm{x}$ & $\mathrm{x}$ & & & \\
\hline Renting of m\&eq and other busin. act. & $71 \mathrm{t} 74$ & $\mathrm{x}$ & $\mathrm{x}$ & & & 1 \\
\hline Public admin and defence; social sec. & $\mathrm{L}$ & $\mathrm{x}$ & $\mathrm{x}$ & & & 1 \\
\hline Education & M & $\mathrm{x}$ & $\mathrm{x}$ & & & 1 \\
\hline Health and social work & $\mathrm{N}$ & $\mathrm{x}$ & $\mathrm{x}$ & & & 1 \\
\hline $\begin{array}{l}\text { Other community, social and personal } \\
\text { services }\end{array}$ & $\mathrm{O}$ & $\mathrm{x}$ & $\mathrm{x}$ & & & 1 \\
\hline $\begin{array}{l}\text { Private households with employed per- } \\
\text { sons }\end{array}$ & $\mathrm{P}$ & $\mathrm{x}$ & $\mathrm{x}$ & & & \\
\hline
\end{tabular}

$1=$ sample of non-energy industries, $2=$ electricity generating sector sample 


\subsection{Sample with Price Information for the Non-Energy Industries}

To construct a data set containing price information in addition to the quantity data used in our main analysis, information on energy factor prices and energy cost shares is added. Cost values are derived by combining the available quantity data with price data taken from the IEA's Energy Prices and Taxes database. It provides energy prices in US\$/toe for 14 different types of energy. These types include: 'steam coal', 'coking coal', 'automotive diesel fuel', 'electricity', 'high sulphur fuel oil', 'premium leaded gasoline', 'regular leaded gasoline', 'light fuel oil', 'liquefied petroleum gas', 'low sulphur fuel oil', 'natural gas', 'premium unleaded 95 RON', 'premium unleaded 98 RON', 'regular unleaded gasoline'. The prices include energy taxes and are calculated by converting national prices using international exchange rates. Prices for three different sectors are published: households, the industrial sector and the electricity generating sector. We use the industrial sector prices. Missing values are replaced with prices from the electricity generating sector (for a similar imputation see Serletis, Timilsina, and Vasetsky (2011)). The energy prices are converted from a tons of oil equivalent (toe) basis into a TJ basis to ensure a common physical unit between price and quantity data. A conversion factor given by the IEA of 1 toe $=0.041868$ TJ is applied.

Using prices and quantities a cost variable for clean as well as for dirty energy is then generated. This is done by multiplying clean energy quantities by the electricity price. ${ }^{10}$ For dirty energy sources the following procedure is applied: first, in order to maximize the available number of observations without neglecting available information, prices for four different energy carrier groups (coal, petroleum, oil, gas) are generated. The steam coal price is used as the coal price but is replaced by the coking coal price if the steam coal price is not available. For oil, the high sulphur fuel oil price is used as standard but is replaced by low sulphur fuel oil price or the light fuel oil price if necessary. In the case of gas the natural gas price is used, whereas for petroleum products there is only the automotive diesel fuel price available. Subsequently, these four price approximations are used to price four groups of energy quantities. The coal price is applied to 'hard coal', 'lignite', and 'coke'; the petroleum price is used for 'diesel', 'gasoline', 'jet fuel', 'other

\footnotetext{
${ }^{10}$ Electricity represents on average $75 \%$ of clean energy used, thus using the electricity price might be an appropriate proxy.
} 
petroleum products' and 'naphtha'; the oil price is applied to the 'light fuel oil', 'heavy fuel oil' and 'crude oil' quantities; the gas price is used for 'natural gas' and 'other gases'. The sum of these energy cost values is then divided by the total sum of energy use, which gives the average energy price for a given year and entity.

\subsection{Appendix to Section 3.2}

If we assume that the energy aggregate and other inputs are used in fixed proportions, the production function (2) reduces to

$$
Y=A_{F}\left[\beta X_{F D}^{\psi_{F}}+(1-\beta) A_{E}^{\psi_{F}}\left(\omega X_{E C}^{\psi_{E}}+(1-\omega) X_{E D}^{\psi_{E}}\right)^{\frac{\psi_{F}}{\psi_{E}}}\right]^{\frac{1}{\psi_{F}}}
$$

To this function we apply the following property shown by Miyagiwa and Papageorgiou (2007): Consider a CES production technology using intermediate inputs $X_{1}$ and $X_{2}$ to produce output $Y$. The intermediate inputs are in turn produced by CES technologies from two factors of production, called clean and dirty in our context (capital and labor in Miyagiwa's and Papageorgiou's context). To save notation we write these CES technologies as $X_{1}\left(X_{1 c}, X_{1 d} ; \sigma_{1}\right), X_{2}\left(X_{2 c}, X_{2 d} ; \sigma_{2}\right)$. Output can then be written as a function of clean and dirty input

$$
Y=\left[\beta X_{1}\left(X_{1 c}, X_{1 d} ; \sigma_{1}\right)^{\frac{\tau-1}{\tau}}+(1-\beta) X_{2}\left(X_{2 c}, X_{2 d} ; \sigma_{2}\right)^{\frac{\tau-1}{\tau}}\right]^{\frac{\tau}{\tau-1}}
$$

Miyagiwa and Papageorgiou (2007) use the dual approach based on Jones (1965) to show that the aggregate elasticity of substitution between the two factors of production is obtained as the following weighted average of the sectoral elasticities

$$
\sigma=\left(\lambda_{1 c} \pi_{1 d}+\lambda_{1 d} \pi_{1 c}\right) \sigma_{1}+\left(\lambda_{2 c} \pi_{2 d}+\lambda_{2 d} \pi_{2 c}\right) \sigma_{2}+\left(\lambda_{1 c}-\lambda_{1 d}\right)\left(\pi_{1 c}-\pi_{1 d}\right) \tau
$$

where $\lambda_{i c}, \lambda_{i d}$ with $i \in\{1,2\}$ are shares of clean and dirty inputs allocated to intermediate technologies 1 and 2 and $\pi_{i c}, \pi_{i d}$ are factor income shares within the intermediate sectors. We apply this result to our function (11) setting

$$
\begin{gathered}
X_{1}=X_{F D} \text { with } \pi_{1 d}=1, \pi_{1 c}=0 \text { and } \lambda_{1 c}=0 \\
X_{2}=A_{E}\left(\omega X_{E C}^{\psi_{E}}+(1-\omega) X_{E D}^{\psi_{E}}\right)^{\frac{1}{\psi_{E}}} \text { with } \lambda_{2 c}=1 \text { and } \sigma_{2}=\frac{1}{1-\psi_{E}} .
\end{gathered}
$$


The elasticity of substitution of the aggregating sector is $\tau=1 /\left(1-\psi_{F}\right)$. The production function (14) representing dirty input into the final sector is linear and thus can be obtained from a CES function by taking the limit when the elasticity of substitution converges to infinity. An infinite elasticity of substitution may look problematic in Equation (13). However, a linear function in which only one factor of production occurs represents a special case where the fraction of the other input and its factor share are already zero before taking the limit. Thus $\lambda_{1 c}=0$ and $\pi_{1 c}=0$ imply that the term $\left(\lambda_{1 c} \pi_{1 d}+\lambda_{1 d} \pi_{1 c}\right) \sigma_{1}$ is also equal to zero. We thus obtain the aggregate elasticity of substitution between clean and dirty inputs as a weighted average of the elasticities in the electricity generating sector and in the final sector

$$
\sigma_{C D}=\left(\pi_{E D}+\lambda_{E D} \pi_{E C}\right) \frac{1}{1-\psi_{E}}+\lambda_{F D} \pi_{E C} \frac{1}{1-\psi_{F}}
$$

